\title{
Esophageal Acidification During Nocturnal Acid-breakthrough with Ilaprazole Versus Omeprazole in Gastroesophageal Reflux Disease
}

\author{
Arun Karyampudi, Uday C Ghoshal, ${ }^{*}$ Rajan Singh, Abhai Verma, Asha Misra, and Vivek A Saraswat \\ Department of Gastroenterology, Sanjay Gandhi Postgraduate Institute of Medical Sciences (SGPGIMS), Lucknow, India
}

\section{Background/Aims}

Though nocturnal acid-breakthrough (NAB) is common in gastroesophageal reflux disease (GERD) patients, its clinical importance results from esophageal acidification, which has been shown to be uncommon. Ilaprazole, a long-acting proton pump inhibitor, may cause NAB infrequently. Accordingly, we studied prospectively, (1) frequency and degree of esophageal acidification during NAB, and (2) frequency and severity of NAB while on ilaprazole versus omeprazole.

\section{Methods}

Fifty-eight consecutive patients with GERD on once daily ilaprazole, $10 \mathrm{mg}(\mathrm{n}=28)$ or omeprazole, $20 \mathrm{mg}(\mathrm{n}=30)$ for $>$ one month underwent 24-hour impedance-pH monitoring prospectively. NAB was defined as intra-gastric $\mathrm{pH}<4$ for $>$ one hour during night, and esophageal acidification as $\mathrm{pH}<4$ for any duration. Nocturnal symptoms (heartburn, regurgitation, and chest pain) were also recorded.

\section{Results}

Of the 58 patients (age 35.5 [inter-quartile range 26.5-46.0] years, 38 [65.5\%], $42(72.4 \%)$ had NAB. Though patients with NAB had lower nocturnal intra-gastric pH than without (2.8 [1.9-4.1] vs 5.7 [4.6-6.8], $P<0.001)$, frequency and duration of nocturnal esophageal acidification (17/42 vs $4 / 16, P=0.360$ and $0.0[0.0-1.0]$ vs $0.0[0.0-0.3]$ minutes, $P=0.260$, respectively) and symptoms were comparable (13/42 vs 6/16, $P=0.750)$. Though ilaprazole was associated with less NABs (1 [range 1-2, $\mathrm{n}=19$ ] vs 1 [range 1-3, $\mathrm{n}=23], P=0.010)$ than omeprazole, the frequency, duration, and mean intra-gastric $\mathrm{pH}$ during NAB were comparable $(19 / 28$ vs $23 / 30, P=0.560 ; 117[0-315]$ vs 159 [69-287] minutes, $P=0.500 ; 1.02[0.7-1.4]$ vs $1.04[0.44-1.3], P=0.620$, respectively).

\section{Conclusions}

Though NAB was common while patients were on a proton pump inhibitor, esophageal acidification was uncommon. Frequency and severity of NAB were comparable among patients on ilaprazole and omeprazole, except for the lesser number of NABs with ilaprazole.

\section{(J Neurogastroenterol Motil 2017;23:208-217)}

\section{Key Words}

Chest pain; Electric impedance; Heartburn; Proton pump inhibitors

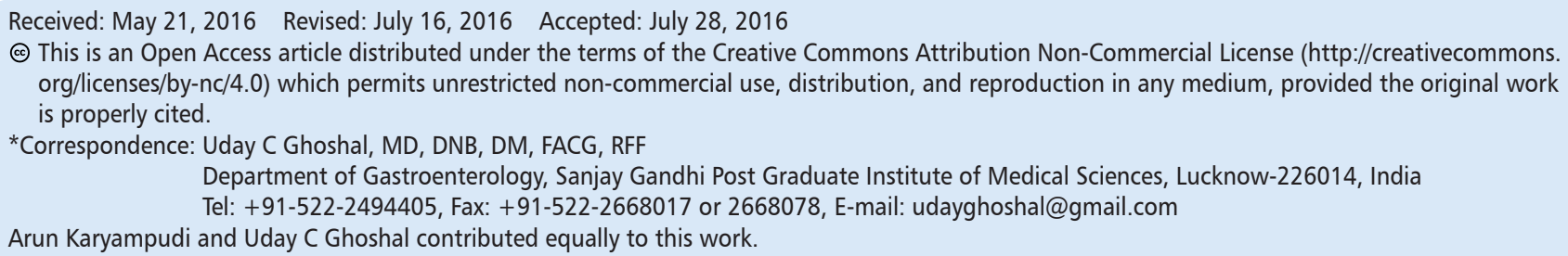




\section{Introduction}

Gastroesophageal reflux disease (GERD) is a common problem in Gastroenterology practice worldwide. Severity of GERD depends largely on the degree and duration of exposure of the esophagus to gastric acid. ${ }^{1-3}$ Pharmacological management of GERD is primarily directed towards suppression of gastric acid secretion, thereby preventing esophageal acid exposure. Nocturnal acid-breakthrough $(\mathrm{NAB})$, defined as persistent reduction of intragastric $\mathrm{pH}$ below 4 for more than 60 minutes during the night, occurs in $40 \%$ to $70 \%$ of patients with GERD while on proton pump inhibitors (PPIs). ${ }^{4-6}$ Though an additional night time dose of PPI and/or histamine $\mathrm{H} 2$ receptor antagonist has been suggested to treat $\mathrm{NAB},{ }^{7}$ the evidence suggesting the need for such treatment is scanty since only a few small studies suggested that NAB is merely a laboratory phenomenon, as esophageal acidification and symptoms are uncommon during $\mathrm{NAB}^{6,8}$

Dual channel 24-hour $\mathrm{pH}$-metry, a technique used to study esophageal acid exposure and intra-gastric $\mathrm{pH}$ over a 24-hour period, has been used to study NAB while on treatment with PPIs. With the advent of multi-channel intra-luminal impedance $\mathrm{pH}$ monitoring, not only acidic reflux, but neutral and weakly acidic refluxes could also be detected..$^{10}$ Though PPIs prevent abnormal esophageal acidification, studies using impedance monitoring suggested that frequency of non-acidic reflux increases on PPI therapy resulting in persistent symptoms. ${ }^{11,12}$ However, the association between degree of gastric acid suppression, occurrence of non-acidic volume reflux and symptoms while on PPI therapy has not been studied, especially in the Asian population.

Ilaprazole, a new PPI with a longer duration of action, has been approved for treatment of duodenal ulcers in some of the Asian countries. In vitro and in vivo data suggest that ilaprazole more potently inhibits gastric acid secretion compared to omeprazole. ${ }^{13}$ While the metabolism of ilaprazole into its major metabolite, ilaprazole sulfone, occurs primarily via CYP3A, it is minimally influenced by CYP2C19 polymorphism, resulting in a predictable dose-response relationship. Though there is adequate data on the clinical efficacy of ilaprazole in patients with duodenal ulcers, data in GERD patients is scanty. Moreover, by the virtue of its long duration of action, it is expected to cause NAB infrequently. However, no study has compared the frequency of $\mathrm{NAB}$ among patients receiving ilaprazole as compared to those receiving omeprazole.

Accordingly, we undertook this prospective study with the following aims: (1) to study nocturnal esophageal acid exposure and symptoms in relation to NAB, (2) to study acid and non-acid volume reflux in relation to degree of gastric acid suppression, and (3) to compare gastric acid profile and severity of NAB between patients on ilaprazole and omeprazole.

\section{Materials and Methods}

\section{Patients}

Consecutive GERD patients attending the Gastroenterology outpatient service of a multi-level teaching hospital were screened prospectively during a 1-year period (between July, 2014 and July, 2015). GERD was diagnosed clinically by the presence of heartburn at least twice a week for a minimum of 6 months, and patients with GERD being treated with omeprazole or ilaprazole at a stable dose of $20 \mathrm{mg}$ and $10 \mathrm{mg}$, respectively, once daily for at least one month were included in the study. Patients taking combination treatments with multiple anti-secretory agents and PPIs other than ilaprazole or omeprazole were excluded, and patients with esophageal strictures or diverticula, hiatus hernias larger than $3 \mathrm{~cm}$, gastric outlet obstruction or neoplasms, peptic ulcers, and history of gastrointestinal surgery in the past were also excluded. The patients were evaluated prospectively by a standard questionnaire (CarlssonDent), physical examination, upper gastrointestinal endoscopy, and high-resolution esophageal manometry. Patients with specific esophageal motor disorders diagnosed by manometry and eosinophilic esophagitis by esophageal biopsy were also excluded. Those who met the inclusion criteria underwent 24-hour impedance $\mathrm{pH}$ metry while on respective PPI (ilaprazole or omeprazole) after informed consent. Institutional Ethics Committee approved the study protocol.

\section{4-hour Impedance pH-metry}

Combined 24-hour impedance $\mathrm{pH}$-metry was performed after an overnight fast using a multi-channel intra-luminal impedance pH (MII-pH) monitoring system (Zephyr; Sandhill scientific, Inc, Highlands Ranch, CO, USA). The combined MII-pH probe had 6 impedance channels (4 located in distal esophagus at 3, 5, 7, and 9 $\mathrm{cm}$ and 2 in the proximal esophagus at $15 \mathrm{~cm}$ and $17 \mathrm{~cm}$ above the lower esophageal sphincter [LES]), and $2 \mathrm{pH}$ sensors placed 15 $\mathrm{cm}$ apart at the end of the probe. Patients who were taking ilaprazole or omeprazole were given the respective PPI (ilaprazole $10 \mathrm{mg}$, or omeprazole $20 \mathrm{mg}$ ) on the day of $\mathrm{pH}$-impedance monitoring on an empty stomach at morning. The $\mathrm{pH}$ probes were calibrated using the standard buffers of $\mathrm{pH} 4.0$ and $\mathrm{pH} 7.0$ prior to each procedure. 
Before the start of $\mathrm{pH}$-metry, all patients underwent high-resolution esophageal manometry using a 32 pressure channel solid state system (Sandhill Scientific, Inc) to localize and measure LES pressure and to study esophageal body motility. After localizing the LES, the proximal $\mathrm{pH}$ probe was placed $5 \mathrm{~cm}$ above it, while the distal probe was placed in the stomach: the former recorded the esophageal $\mathrm{pH}$ while the latter recorded the gastric $\mathrm{pH}$ during the 24-hour period. Patients were allowed to carry out their regular activities and take regular meals but were advised not to take sour foods during the study period. A symptom diary was given to every patient to record change in posture, intake of meals, and symptoms experienced during the study period. After the 24-hour study, data was transferred from the data logger to a computer for further analysis of esophageal acid exposure (mean esophageal $\mathrm{pH}, \%$ time $\mathrm{pH}$ less than 4 , and $\%$ time $\mathrm{pH}$ less than 4 during upright and supine postures), gastric acid profile (mean gastric $\mathrm{pH}$ and $\%$ time gastric $\mathrm{pH}$ less than 4), and bolus exposure using impedance measurement.

\section{Analysis of Nocturnal Period and Nocturnal Acid-breakthrough}

The nocturnal period was defined as the time period between $10 \mathrm{PM}$ and $6 \mathrm{AM}$, while the rest of the day before $10 \mathrm{PM}$ was considered as day time. $\mathrm{NAB}$ was defined as a drop in intra-gastric $\mathrm{pH}$ of less than 4 continuously for more than one hour during the nocturnal period. Nocturnal esophageal acidification was defined as a drop in esophageal $\mathrm{pH}$ of less than 4 for any duration during the night time. Heartburn, regurgitation, and chest pain were considered as reflux symptoms during the night time.

\section{4-hour pH and Impedance Analysis}

Abnormal 24-hour esophageal acid exposure was considered when percentage time esophageal $\mathrm{pH}$ was less than 4 for more than $4.2 \%$ on 24 -hour $\mathrm{pH}$-metry. ${ }^{14-16}$ Patients were classified as combined esophageal acid refluxers if the $\%$ time esophageal $\mathrm{pH}$ less than 4 during upright and supine postures were more than 6.3 and 1.2 , respectively, during the 24-hour period.

Liquid bolus exposure was defined as a retrograde drop in impedance by $50 \%$ of the baseline. Abnormal 24-hour esophageal bolus exposure by impedance was defined as the $\%$ time bolus exposure of more than $1.4 \%$. Combined GERD was defined as having the $\%$ time bolus exposure during upright and supine postures of more than 2.1 and 0.7 , respectively, during the 24-hour period. Impedance detected reflux episodes were classified as "acid" if the $\mathrm{pH}$ sensor recorded a decline in $\mathrm{pH}$ below 4, or "non-acid" if the $\mathrm{pH}$ remained above 4 during presence of the bolus in esophagus.
Similar to symptoms at night, heartburn, regurgitation, and chest pain were considered as reflux symptoms during the 24hour study period. Symptom index was defined as the number of symptoms associated with reflux divided by the total number of symptoms. A positive symptom index was declared if $\geq 50 \%$ of symptoms were associated with reflux.

\section{Statistical Methods}

Continuous data were expressed as median and inter-quartile ranges (IQR). Frequency was expressed as a percentage (\%). Continuous and categorical data among various groups were compared using the Mann-Whitney U test and Chi-square test, with Yates' correction as applicable, respectively. $P$-values below 0.05 were considered significant. A biomedical scientist well-conversant with statistical analysis performed and reviewed the analyses. All analyses were done using R, Epicalc, and R-studio software (R development core team, Vienna, Austria) and SPSS version 15 (SPSS, Inc, Chicago, IL, USA).

\section{Results}

Seventy patients with GERD who were taking ilaprazole, 10 $\mathrm{mg}(\mathrm{n}=34)$ or omeprazole, $20 \mathrm{mg}(\mathrm{n}=36)$ once daily for at least a month were initially screened. Five patients with large hiatal hernias ( 3 on ilaprazole and 2 on omeprazole), three with active duodenal ulcers ( 1 on ilaprazole and 2 on omeprazole), and three on multiple anti-secretory drugs ( 1 on ilaprazole and 2 on omeprazole) were excluded. All remaining patients underwent 24-hour impedance $\mathrm{pH}$ metry while on respective PPI. Data from one patient on ilaprazole were not available due to technical problems precluding further analysis. Data from the rest of the 58 patients were available for further analysis (Fig. 1). Patients were of median (IQR) age 35.5 (26.5-46.0) years and were predominantly male, 38 (65.5\%). All patients had heartburn, 35 (60.3\%) had regurgitation, and both symptoms were present for long duration (median [IQR] 36 [1860] and 24 [0-48] months, respectively). Of these 58 patients, 15 (26\%) had chest pain, 25 (43\%) had upper abdominal pain, 6 (10.3\%) had bronchial asthma, $20(34.5 \%)$ had dental caries, and $13(22.4 \%)$ had disturbed sleep at night due to GERD symptoms.

\section{Analysis of Nocturnal Period and Nocturnal Acid-breakthrough}

Of the 58 patients, $42(72.4 \%)$ had NAB while on once daily PPI. Male patients showed a trend to have NAB more frequently compared to female patients (31 [73.8\%] vs $7[43.8 \%], P=0.061)$ 


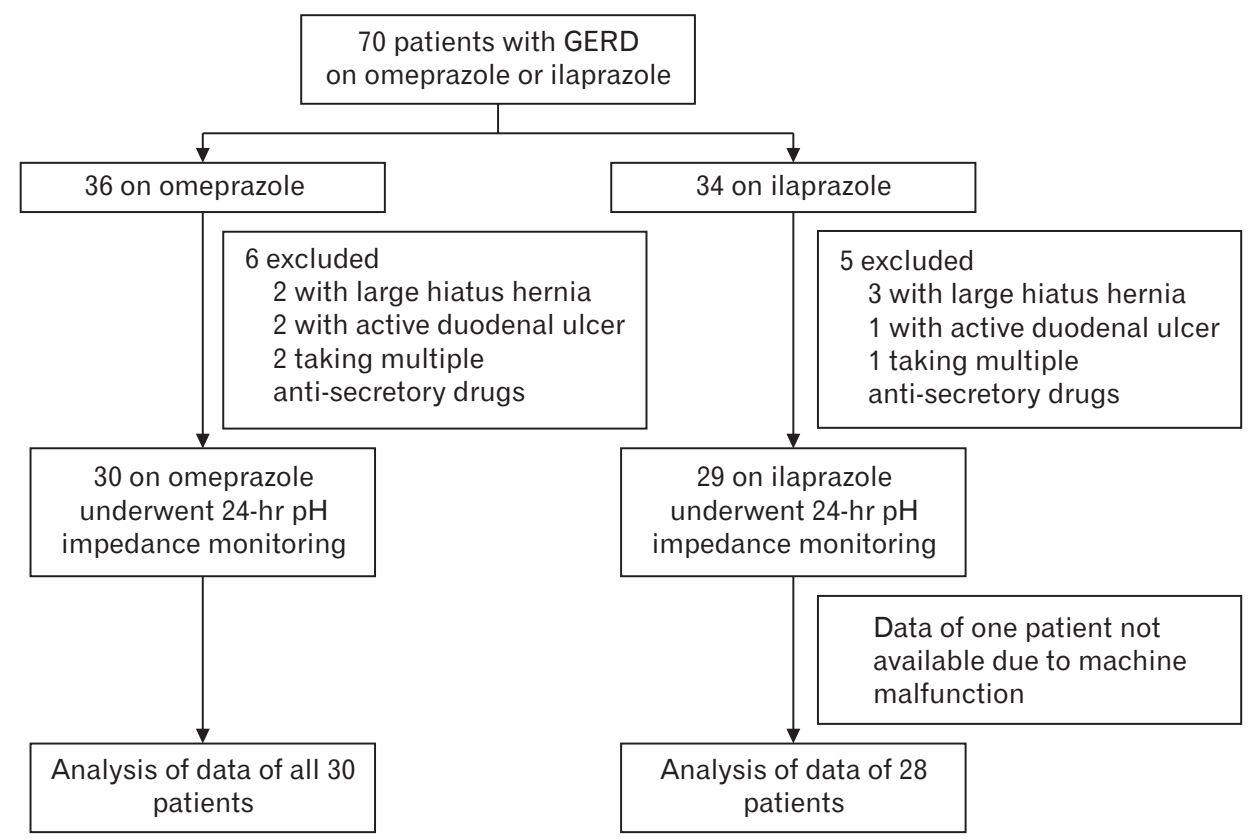

Figure 1. Flow diagram showing the distribution of patients in the study. GERD, gastroesophageal reflux disease.

Table 1. Baseline Demographic and Esophageal Manometric Parameters in Relation to Nocturnal Acid-breakthrough and Proton Pump Inhibitors

\begin{tabular}{|c|c|c|c|c|c|c|}
\hline Parameters & $\begin{array}{l}\text { NAB present } \\
\quad(\mathrm{n}=42)\end{array}$ & $\begin{array}{l}\text { NAB absent } \\
(\mathrm{n}=16)\end{array}$ & $P$-value & $\begin{array}{c}\text { Ilaprazole } \\
(\mathrm{n}=28)\end{array}$ & $\begin{array}{c}\text { Omeprazole } \\
(\mathrm{n}=30)\end{array}$ & $P$-value \\
\hline Age (yr) & $34.0(24.7-40.0)$ & $40.5(33.5-48.0)$ & 0.089 & $38.0(27.0-48.7)$ & $34.0(26.0-38.0)$ & 0.080 \\
\hline Male sex (n [\%]) & $31(73.8)$ & $7(43.8)$ & 0.061 & $17(60.7)$ & $21(70.0)$ & 0.582 \\
\hline Weight (kg) & $61.5(52.0-70.0)$ & $58.0(52.7-72.0)$ & 0.828 & $61.0(51.2-70.0)$ & $60.0(52.0-68.7)$ & 0.833 \\
\hline Height (cm) & $164.0(159.5-172.0)$ & $160.0(149.0-165.0)$ & 0.070 & $162.0(158.5-165.0)$ & $165.0(156.0-174.0)$ & 0.170 \\
\hline $\operatorname{BMI}\left(\mathrm{kg} / \mathrm{m}^{2}\right)$ & $22.6(19.7-25.4)$ & $24.3(21.8-25.5)$ & 0.095 & $23.5(19.8-27.2)$ & $22.7(20.9-24.4)$ & 0.423 \\
\hline Symptom duration (mo) & $36.0(12.0-66.0)$ & $42.0(27.0-60.0)$ & 0.396 & $42.0(24.0-78.0)$ & $36.0(16.5-60.0)$ & 0.511 \\
\hline Carlsson Dent score & $14.0(12.0-15.0)$ & $12.5(11.0-15.5)$ & 0.661 & $14.0(11.2-15.0)$ & $13.0(11.0-15.0)$ & 0.397 \\
\hline LES pressure (mmHg) & $16.0(8.0-22.0)$ & $15.0(10.0-24.0)$ & 0.932 & $12.5(9.0-26.0)$ & $16.5(7.2-22.0)$ & $>0.99$ \\
\hline $\mathrm{DCI}(\mathrm{mmHg} \cdot \mathrm{sec} \cdot \mathrm{cm})$ & $869.0(543.2-1406.2)$ & $616.0(234.0-881.5)$ & 0.071 & $738.0(462.5-1012.5)$ & $822.5(461.7-1406.2)$ & 0.550 \\
\hline IRP (mmHg) & $5.7(3.0-9.2)$ & $6.0(5.0-10.0)$ & 0.349 & $6.0(4.0-9.0)$ & $6.0(3.0-9.8)$ & 0.742 \\
\hline $\mathrm{CFV}(\mathrm{cm} / \mathrm{sec})$ & $4.0(2.8-5.3)$ & $3.4(3.0-4.0)$ & 0.222 & $3.7(2.4-5.1)$ & $4.0(3.3-5.0)$ & 0.200 \\
\hline Lax LES (n [\%]) & $13(32.5)$ & $2(13.3)$ & 0.192 & $8(29.6)$ & $7(25.0)$ & 0.768 \\
\hline Failed peristalsis (n [\%]) & $3(7.5)$ & $3(20.0)$ & 0.329 & $3(11.1)$ & $3(10.7)$ & $>0.99$ \\
\hline
\end{tabular}

$\mathrm{NAB}$, nocturnal acid-breakthrough; BMI, body mass index; LES, lower esophageal sphincter; DCI, distal contractile integral; IRP, integrated relaxation pressure; $\mathrm{CFV}$, contractile front velocity.

All values are in median (inter-quartile range) unless otherwise specified.

(Table 1). Similarly, patients with NAB showed a trend towards being younger, taller, and having lower BMI compared to those without (34 [24.7-40.0] vs 40.5 [33.5-48.0] years, $P=0.089 ; 164$ [159.5-172] vs 160 [149-165] cm, $P=0.070 ; 22.6$ [19.7-25.4] vs $24.3[21.8-25.5] \mathrm{kg} / \mathrm{m}^{2}, P=0.095$; respectively). Symptom duration was comparable between patients with and without NAB. On esophageal manometry, patients with NAB showed a trend towards a higher distal contractile integral than those without (869.0
[543.2-1406.2] vs 616.0 (234.0-881.5), $P=0.071)$. However, LES pressure, integrated relaxation pressure, and contractile front velocity were comparable between patients with and without NAB.

Though patients with NAB had a lower nocturnal mean gastric $\mathrm{pH}$ compared to those without (2.8 [1.9-4.1] vs 5.7 [4.66.8], $P<0.001)$, the nocturnal mean esophageal $\mathrm{pH}$, duration of esophageal $\mathrm{pH}$ below 4 , and frequency of esophageal acidification at night were comparable between patients with and without 
NAB (Table 2 and Fig. 2A). Thirteen (31\%) of 42 patients with $\mathrm{NAB}$ and $6(37.5 \%)$ of 16 patients without, reported nocturnal reflux symptoms $(P=\mathrm{NS})$. Moreover, the number of nocturnal symptoms reported per patient was also similar in patients with and without NAB (Fig. 2B). Sixteen of 17 (94\%) and 10 of 13 (77\%) patients who had NAB with nocturnal esophageal acidification and symptoms, respectively, experienced the events during NAB.

\section{4-hour pH and Impedance Analysis in Relation to Nocturnal Acid-breakthrough}

Patients with $\mathrm{NAB}$ had lower mean gastric $\mathrm{pH}$ and longer duration of gastric $\mathrm{pH}$ below 4 compared to those without NAB during the 24 -hour period $(2.7[1.8-3.5]$ vs 6 [4.5-6.8], $P<$ 0.001 and $73.5[56.8-84.0]$ vs $9.4[2.5-40.0] \%$ time, $P<0.001$; respectively) (Table 3 ). Though patients with NAB showed a trend towards longer duration of esophageal $\mathrm{pH}$ below 4 (0.2 [0-1.4.0] vs 0.0 [0.0-0.3] \% time, $P=0.070)$, mean esophageal $\mathrm{pH}$ and frequency of abnormal esophageal acid exposure during the 24-hour period were comparable between patients with and without NAB.

Patients without NAB had longer duration of bolus exposure and more frequent combined abnormal bolus exposure by 24-hour impedance monitoring than those with NAB (2.6 [1.4-6.9] vs 1.2 [0.7-3.0] \% time, $P=0.019$ and 12 (75\%) vs 14 (33.3\%), $P=$ 0.007; respectively) (Fig. 3A). Moreover, patients without NAB showed a trend towards more frequent abnormal bolus exposure than those with $\mathrm{NAB}$ (12 [75\%] vs 19 [45.2\%], $P=0.076)$.

Though frequency of reflux symptoms during the 24-hour period was comparable between patients with and without NAB, patients without NAB had a higher symptom index (SI) for nonacid reflux than those with NAB (41.6 [0.0-84.1] vs 0.0 [0.0-28.2], $P=0.008$ ) (Fig. 3B). Similarly, 8 (50\%) of 16 without NAB had positive SI for non-acid reflux compared to 4 (9.5\%) of 42 with NAB $(P=0.002)$. Symptom index for acid reflux and frequency of positive SI for acid reflux were comparable between patients with and without NAB.

Table 2. Summary of Nocturnal Period Analysis in Relation to Nocturnal Acid-breakthrough

\begin{tabular}{lccr}
\hline \multicolumn{1}{c}{ Parameters } & $\begin{array}{c}\text { NAB present } \\
(\mathrm{n}=42)\end{array}$ & $\begin{array}{c}\text { NAB absent } \\
(\mathrm{n}=16)\end{array}$ & $P$-value \\
\hline Nocturnal esophageal acidification (n [\%]) & $17(40.5)$ & $4(25.0)$ & 0.365 \\
Nocturnal symptoms (n [\%]) & $13(31.0)$ & $6(37.5)$ & 0.756 \\
Nocturnal mean esophageal pH & $6.2(5.8-6.4)$ & $6.0(5.5-6.5)$ & 0.560 \\
Nocturnal mean gastric pH & $2.8(1.9-4.1)$ & $5.7(4.6-6.8)$ & $<0.001$ \\
\hline
\end{tabular}

$\mathrm{NAB}$, nocturnal acid-breakthrough.

All values are in median (inter-quartile range) unless otherwise specified.

$A$

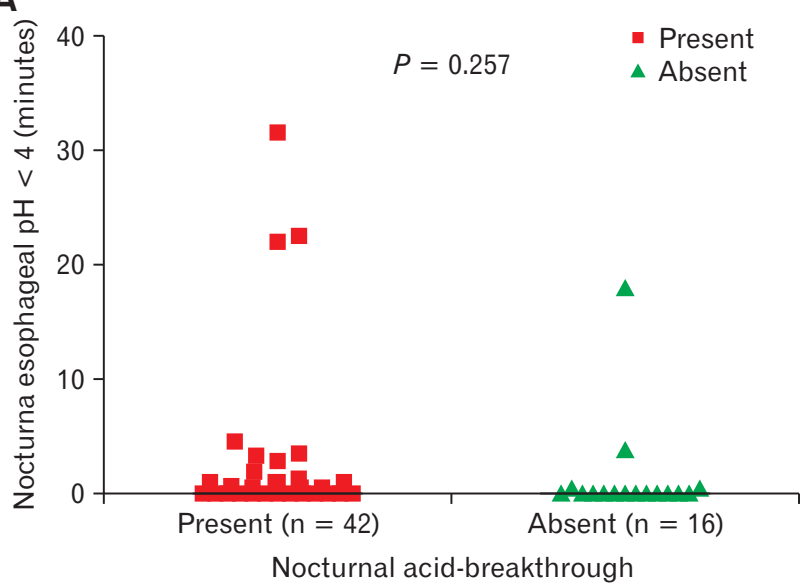

B

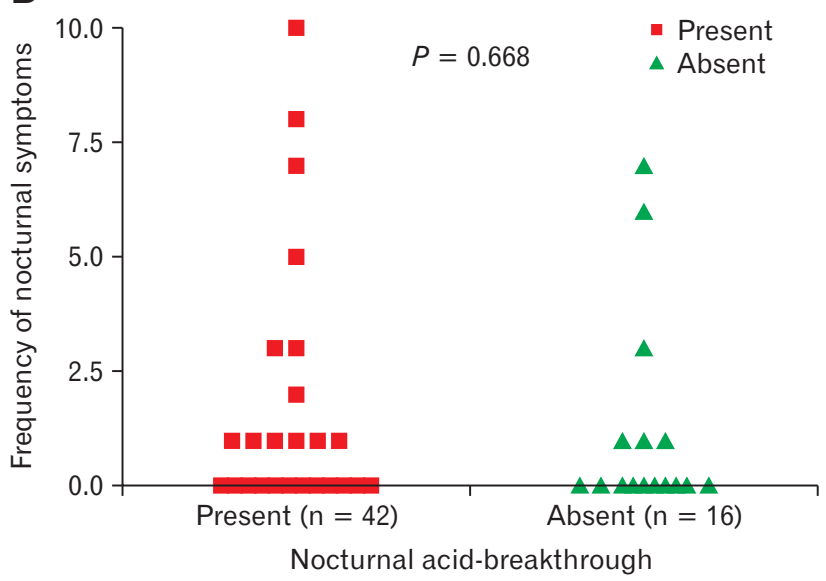

Figure 2. Comparison of duration of nocturnal esophageal acidification (A) and frequency of nocturnal symptoms (B) between patients with and without nocturnal acid-breakthrough. 
Table 3. Summary of 24-hour $\mathrm{pH}$ and Impedance Parameters in Relation to Nocturnal Acid-breakthrough

\begin{tabular}{|c|c|c|c|}
\hline Parameters & $\begin{array}{l}\text { NAB present } \\
\quad(n=42)\end{array}$ & $\begin{array}{c}\text { NAB absent } \\
(\mathrm{n}=16)\end{array}$ & $P$-value \\
\hline Mean gastric $\mathrm{pH}$ & $2.7(1.8-3.5)$ & $6.0(4.5-6.8)$ & $<0.001$ \\
\hline$\%$ time gastric $\mathrm{pH}<4$ & $73.5(56.8-84.0)$ & $9.4(2.5-40.0)$ & $<0.001$ \\
\hline Mean esophageal $\mathrm{pH}$ & $6.3(5.9-6.6)$ & $6.3(5.8-6.6)$ & 0.848 \\
\hline$\%$ time esophageal $\mathrm{pH}<4$ & $0.2(0.0-1.4)$ & $0.0(0.0-0.3)$ & 0.070 \\
\hline Abnormal esophageal acid exposure (n [\%]) & $6(14.3)$ & $1(6.2)$ & 0.660 \\
\hline Abnormal esophageal combined acid reflux (n [\%]) & $3(7.1)$ & $1(6.2)$ & $>0.99$ \\
\hline Abnormal bolus exposure (n [\%]) & $19(45.2)$ & $12(75.0)$ & 0.076 \\
\hline Abnormal combined bolus exposure (n [\%]) & $14(33.3)$ & $12(75.0)$ & 0.007 \\
\hline Reflux symptoms per patient & $6.0(2.0-18.5)$ & $2.5(1.0-25.5)$ & 0.355 \\
\hline SI for acid reflux (\%) & $0.0(0.0-29.2)$ & $0.0(0.0-5.0)$ & 0.169 \\
\hline Positive SI for acid reflux (n [\%]) & $4(9.5)$ & $1(6.2)$ & $>0.99$ \\
\hline Positive SI for non-acid reflux (n [\%]) & $4(9.5)$ & $8(50.0)$ & 0.002 \\
\hline Positive SI for all reflux (n [\%]) & $12(28.6)$ & $9(56.2)$ & 0.069 \\
\hline
\end{tabular}

$\mathrm{NAB}$, nocturnal acid-breakthrough; SI, symptom index

All values are in median (inter-quartile range) unless otherwise specified.

A

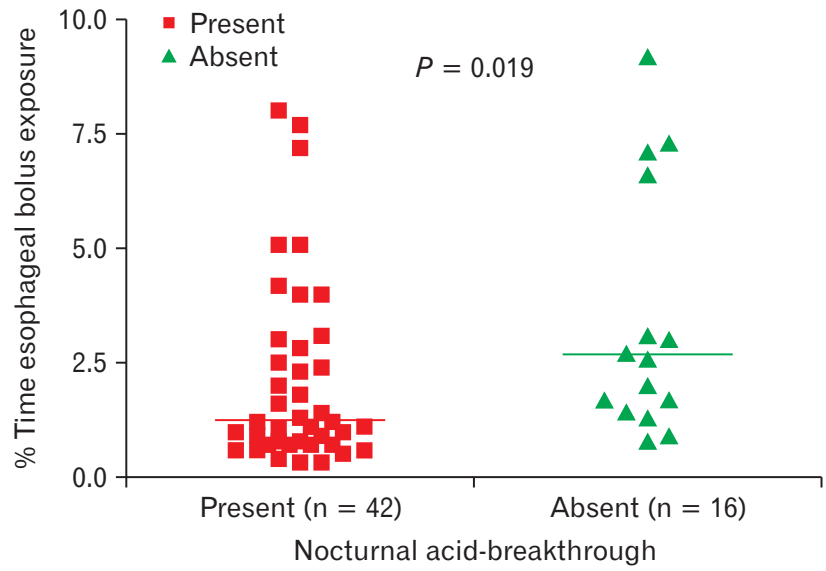

B

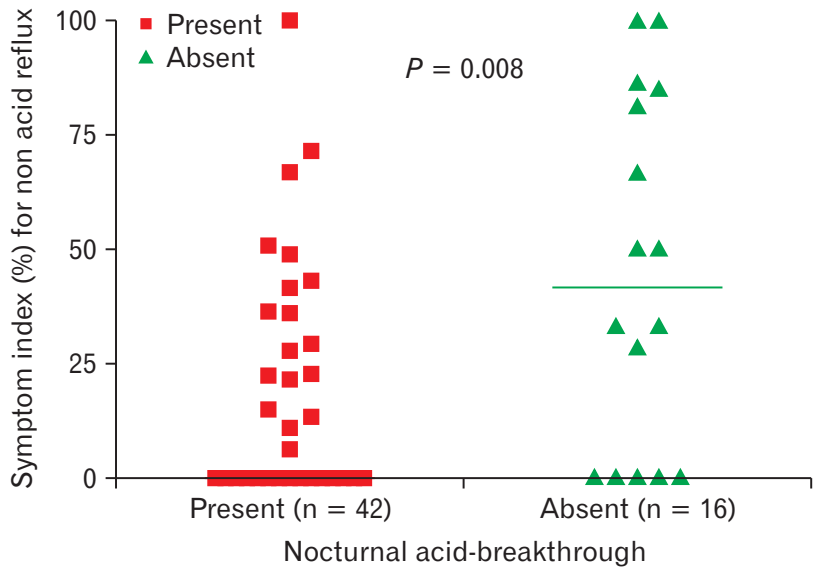

Figure 3. Comparison of percent time esophageal bolus exposure (A) and symptom index for non-acid reflux (B) between patients with and without nocturnal acid-breakthrough during 24-hour impedance monitoring.

\section{Ilaprazole Versus Omeprazole}

Demographic and esophageal manometric parameters at the time of entry into the study were comparable between ilaprazole and omeprazole groups (Table 1). Mean gastric $\mathrm{pH}, \%$ time gastric $\mathrm{pH}$ below 4 , mean esophageal $\mathrm{pH}$ and $\%$ time esophageal $\mathrm{pH}$ below 4 were comparable between ilaprazole and omeprazole groups during the 24-hour period (Table 4). Three (10.7\%) of 28 patients in the ilaprazole group and $4(13.3 \%)$ of 30 patients in the omeprazole group had abnormal esophageal acid exposure during the 24-hour period $(P=\mathrm{NS})$. Frequency and duration of NAB and mean gastric $\mathrm{pH}$ during $\mathrm{NAB}$ were comparable between both groups (19/28 vs $23 / 30, P=0.450 ; 117$ [0-321] vs 159 [66-300] minutes, $P=$ $0.500 ; 1.02[0.72-1.38]$ vs $1.04[0.44-1.30], P=0.630$, respectively). Among those who had NAB, lesser number of NAB episodes occurred in the ilaprazole group compared to the omeprazole group (1 [range 1-2, $\mathrm{n}=19$ ] vs 1 [range $1-3, \mathrm{n}=23$ ],$P=0.010)$ (Fig. 4). Reflux symptoms during the 24-hour and nocturnal period occurred with comparable frequency between both groups. 
Table 4. Summary of 24-hour and Nocturnal $\mathrm{pH}$ and Impedance Parameters in Relation to Proton Pump Inhibitor

\begin{tabular}{|c|c|c|c|}
\hline Parameters & $\begin{array}{l}\text { Ilaprazole } \\
(\mathrm{n}=28)\end{array}$ & $\begin{array}{l}\text { Omeprazole } \\
(\mathrm{n}=30)\end{array}$ & $P$-value \\
\hline 24-hr mean gastric $\mathrm{pH}$ & $3.3(2.2-4.2)$ & $3.3(1.8-4.8)$ & 0.889 \\
\hline$\%$ time $^{\mathrm{a}}$ gastric $\mathrm{pH}<4$ & $65.0(46.3-80.0)$ & $57.9(37.3-81.1)$ & 0.926 \\
\hline 24-hr mean esophageal $\mathrm{pH}$ & $6.3(6.1-6.7)$ & $6.2(5.8-6.5)$ & 0.194 \\
\hline$\%$ time $^{\mathrm{a}}$ esophageal $\mathrm{pH}<4$ & $0.1(0.0-1.3)$ & $0.2(0.1-1.5)$ & 0.336 \\
\hline 24-hr abnormal esophageal acid exposure (n [\%]) & $3(10.7)$ & $4(13.3)$ & $>0.99$ \\
\hline$\%$ time $^{\mathrm{a}}$ esophageal bolus exposure & $1.7(1.0-3.1)$ & $1.2(0.8-4.0)$ & 0.646 \\
\hline 24-hr abnormal bolus exposure (n [\%]) & $17(60.7)$ & $14(46.7)$ & 0.306 \\
\hline 24-hr reflux symptoms & $4.0(1.2-7.7)$ & $9.0(1.7-29.2)$ & 0.175 \\
\hline NAB frequency (n [\%]) & $19(67.9)$ & $23(76.7)$ & 0.561 \\
\hline Nocturnal esophageal acidification (n [\%]) & $10(35.7)$ & $11(36.7)$ & $>0.99$ \\
\hline Nocturnal mean esophageal $\mathrm{pH}$ & $6.2(5.8-6.5)$ & $6.0(5.7-6.3)$ & 0.196 \\
\hline Nocturnal mean gastric $\mathrm{pH}$ & $4.3(2.4-5.3)$ & $3.5(2.2-4.6)$ & 0.276 \\
\hline Nocturnal symptoms (n [\%]) & $10(35.7)$ & $9(30.0)$ & 0.781 \\
\hline Nocturnal symptoms & $0(0-1)$ & $0(0-1)$ & 0.925 \\
\hline
\end{tabular}

${ }^{a}$ Percent time of 24-hour period.

$\mathrm{NAB}$, nocturnal acid-breakthrough.

All values are in median (inter-quartile range) unless otherwise specified.
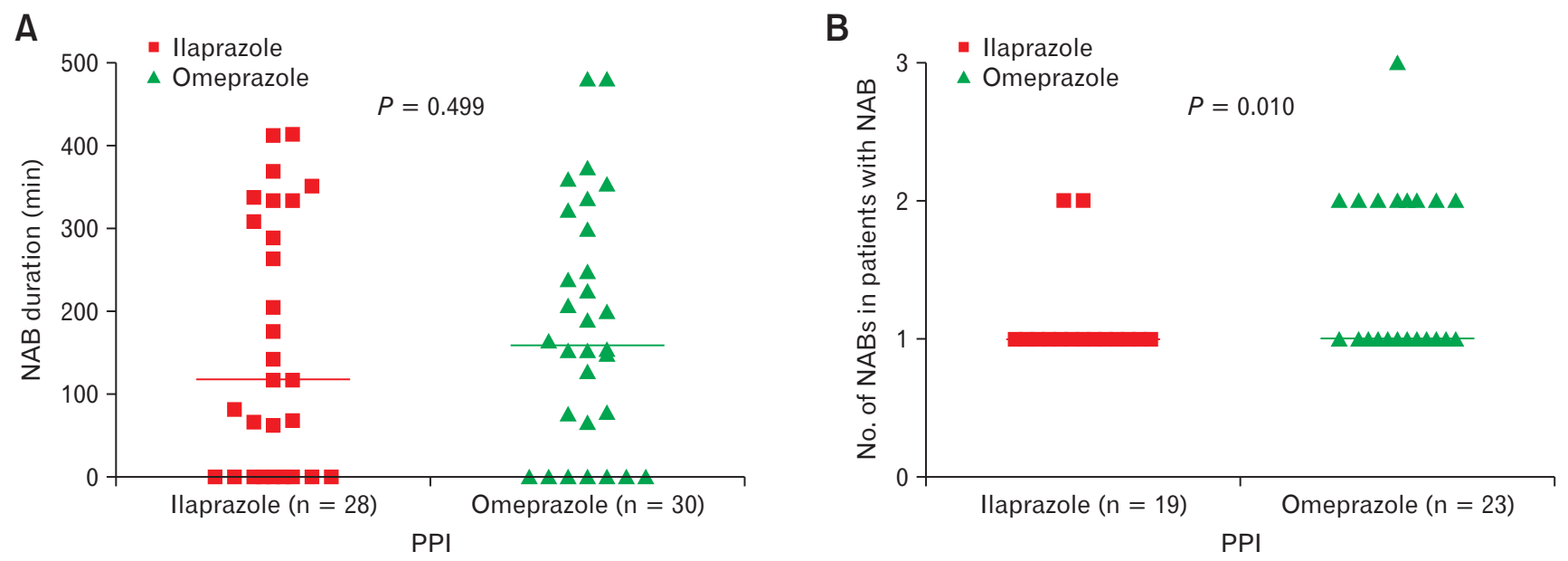

C

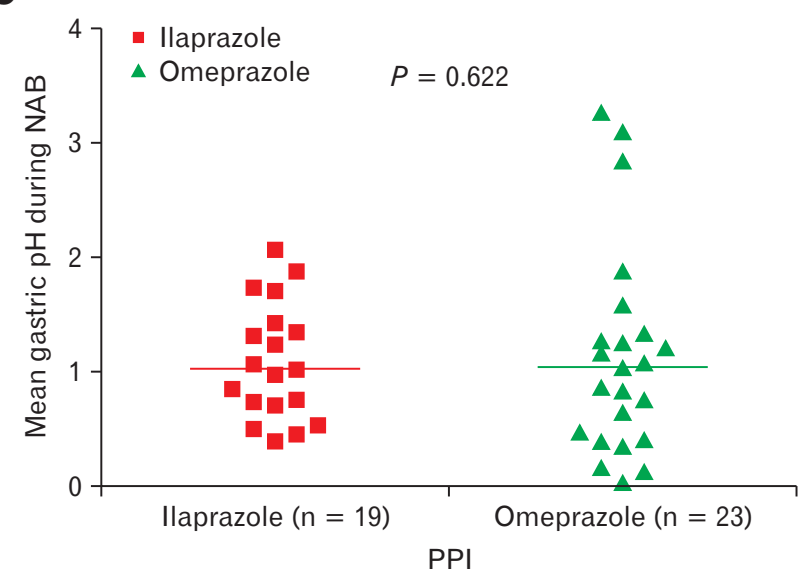

Figure 4. Comparison of duration (A), number of nocturnal acidbreakthrough (NAB) episodes $(\mathrm{B})$ and mean gastric $\mathrm{pH}$ during $\mathrm{NAB}$ (C) between patients on ilaprazole and omeprazole. PPI, proton pump inhibitor. 


\section{Discussion}

This study shows that (1) frequency of NAB was high (72\%) while on once daily treatment with PPI, (2) frequency and duration of nocturnal esophageal acidification and nocturnal symptoms were comparable in patients with and without NAB, (3) though patients without $\mathrm{NAB}$ had greater degree of gastric acid suppression, the frequency of abnormal non-acidic volume reflux by impedance was higher compared to patients with $\mathrm{NAB}$, and (4) the frequency, duration, and mean intra-gastric $\mathrm{pH}$ during $\mathrm{NAB}$ were comparable between ilaprazole and omeprazole groups.

Since the concept of NAB was introduced in 1998, some investigators believed that NAB might be responsible for PPI refractory GERD symptoms and made attempts to abolish it by doubling the dose of PPI or adding a histamine $\mathrm{H} 2$ receptor blocker at bedtime. ${ }^{17} \mathrm{NAB}$ was as high as $90 \%$ in patients taking once daily omeprazole in one study. ${ }^{4} \mathrm{Katz}$ et $\mathrm{al}^{5}$ showed that NAB occurred in $70 \%$ of patients with GERD while taking twice daily omeprazole. ${ }^{5}$ Similar results were shown by other studies as well using twice daily omeprazole. ${ }^{18-20,21}$ On the contrary, one of our previous studies showed lower frequency of $\mathrm{NAB}$ among patients taking once daily omeprazole, though the number of patients studied was less than that in the present study. ${ }^{6}$ Overall, the high frequency of NAB observed in our study with use of once daily omeprazole or ilaprazole was consistent with results of most of the other studies. A plausible explanation for this phenomenon is that PPIs, when taken once daily in the morning or taken at night without meals, do not inhibit the proton pumps that are in the renewal stage at night.

Clinical importance of NAB depends on its ability to cause esophageal acidification at night, which when present may increase mucosal injury in patients with erosive esophagitis and may contribute to extra-esophageal manifestations of GERD. ${ }^{22}$ Scanty data are available in the literature on this issue. While some studies suggest that NAB is merely a laboratory phenomenon limited to the stomach and is not associated with esophageal acidification, ${ }^{6,8}$ other studies have suggested differently. ${ }^{5,18}$ In our previous study mentioned above, ${ }^{6}$ esophageal acid exposure and nocturnal symptoms in patients with or without $\mathrm{NAB}$ were comparable in a small group of 18 patients. Ours et $\mathrm{al}^{8}$ showed that, though NAB was a frequent phenomenon on PPI therapy, 24-hour esophageal acid reflux and symptoms were well controlled after therapy. However, this study had limitations, as it was performed in a small sample of patients, and the investigators did not specifically look at nocturnal esophageal acidification and nocturnal symptoms. Katz et al $l^{5}$ showed that esophageal acid exposure could occur in up to $40 \%$ of GERD patients with $\mathrm{NAB}$, with a higher frequency observed in patients with Barrett's. Though this study had a larger sample size, it was retrospective in nature and nocturnal symptoms were not adequately studied. Xue et $\mathrm{al}^{18}$ suggested possible correlation between gastric acid levels and supine esophageal acid exposure in a small group of patients. However, investigators in this study did not examine the effect of NAB on esophageal acid exposure and nocturnal symptoms. Our study is perhaps the first prospective study with a larger sample size to show that esophageal acid exposure and nocturnal symptoms occurred with similar frequency in patients with or without NAB.

Though we found that only a small proportion of our patients had abnormal 24-hour esophageal acid reflux, almost half of the patients had abnormal 24-hour esophageal bolus exposure by impedance while on PPI therapy. This is consistent with other studies that investigated non-acidic reflux in patients who were non-responsive to PPI therapy. ${ }^{23-25}$ Mainie et al ${ }^{12}$ performed impedance $\mathrm{pH}$ monitoring in $168 \mathrm{PPI}$ non-responsive GERD patients while on twice daily PPI. While $40 \%$ of symptoms were related to non-acid reflux, only $10 \%$ of symptoms were related to acid reflux. ${ }^{12}$ Vela et $\mathrm{al}^{11}$ suggested that, on omeprazole, the percentage of acid reflux decreased from $45 \%$ to $3 \%$ but that of non-acid reflux increased from 55\% to $97 \% .^{11}$ Though PPIs are highly effective in neutralizing gastric acid and preventing esophageal acidification, non-acidic liquid reflux remains to be a significant problem in a large proportion of patients. ${ }^{10,26}$ The association between degree of gastric acid suppression and occurrence of non-acidic reflux has not been studied adequately. We found that patients without NAB, who had greater degree of gastric acid suppression, had more frequent abnormal 24hour esophageal bolus exposure and positive symptom index for non-acid reflux than patients with NAB. This phenomenon has not been reported previously in literature and could possibly explain the comparable frequency of symptom occurrence in patients with and without NAB in our study.

Ilaprazole, a newer PPI, predominantly metabolized by CYP3A4 enzyme in the Asian population, ${ }^{27}$ has been shown to be minimally influenced by CYP2C19 and CYP3A5 polymorphism. ${ }^{28-30}$ Accordingly, ilaprazole is expected to have a longer duration of action and less NAB compared to other PPIs. ${ }^{31,32}$ But we found that GERD symptoms, 24-hour mean gastric $\mathrm{pH}$, nocturnal mean gastric $\mathrm{pH}$, frequency and duration of $\mathrm{NAB}$, were comparable between the ilaprazole and omeprazole groups. The only significant difference was occurrence of lesser number of NAB episodes in the ilaprazole group. Acid suppression properties of omeprazole were 
consistent with other studies ${ }^{33-35}$ but that of ilaprazole were found to be inferior compared to previous studies. ${ }^{36,37}$ This could be explained by probable altered metabolism of ilaprazole in our population compared to other Asian populations, and the higher dose of ilaprazole could have produced better acid suppression than the 10 mg used in our study. However, our study is the first to demonstrate the effect of ilaprazole on NAB in GERD patients.

Our study has some limitations. First of all, we could have missed some cases of functional heartburn as we did not perform 24-hour impedance $\mathrm{pH}$ metry in patients off PPI. However, we believe that patients with functional heartburn form only a small proportion of those presenting with heartburn as shown by previous studies. ${ }^{38,39}$ Secondly, we did not study the pharmacokinetics of the drugs and CYP enzyme polymorphism in our population. Finally, we did not study Helicobacter pylori status systematically in our patients as it was not in the original aim of the study.

In conclusion, though the frequency of NAB while on PPI was high, nocturnal esophageal acidification was uncommon. Patients without $\mathrm{NAB}$, though had greater degree of gastric acid suppression, experienced more symptoms related to non-acid reflux compared to patients with NAB. Ilaprazole, when given at $10 \mathrm{mg}$ once daily, was comparable to omeprazole $20 \mathrm{mg}$ in terms of frequency and severity of $\mathrm{NAB}$, except for occurrence of lesser number of $\mathrm{NAB}$ episodes. Whether increasing the dose of ilaprazole will produce greater acid suppression or not should be confirmed in future studies with a larger sample size.

Acknowledgements: Authors thank all the subjects for participating in the study.

\section{Financial support: None.}

\section{Conflicts of interest: None.}

Author contributions: Arun Karyampudi and Uday C Ghoshal designed the research and wrote the paper; Rajan Singh, Abhai Verma, Uday C Ghoshal, and Asha Misra performed the research; Arun Karyampudi, Rajan Singh, and Uday C Ghoshal analyzed the data; and Vivek A Saraswat supervised the work and edited the paper.

\section{References}

1. Cadiot G, Bruhat A, Rigaud D, et al. Multivariate analysis of pathophysiological factors in reflux oesophagitis. Gut 1997;40:167-174.

2. Armstrong D. Review article: gastric $\mathrm{pH}$--the most relevant predictor of benefit in reflux disease? Aliment Pharmacol Ther 2004;20(suppl 5):19-26; discussion 38-39.

3. Bremner RM, Crookes PF, DeMeester TR, Peters JH, Stein HJ. Concentration of refluxed acid and esophageal mucosal injury. Am J Surg 1992;164:522-526;discussion 526-527.

4. Nzeako UC, Murray JA. An evaluation of the clinical implications of acid breakthrough in patients on proton pump inhibitor therapy. Aliment Pharmacol Ther 2002;16:1309-1316.

5. Katz PO, Anderson C, Khoury R, Castell DO. Gastro-oesophageal reflux associated with nocturnal gastric acid breakthrough on proton pump inhibitors. Aliment Pharmacol Ther 1998;12:1231-1234.

6. Ghoshal UC, Chourasia D, Tripathi S, Singh K. Relationship of severity of gastroesophageal reflux disease with gastric acid secretory profile and esophageal acid exposure during nocturnal acid breakthrough: a study using 24-h dual-channel pH-metry. Scand J Gastroenterol 2008;43:654661.

7. Fackler WK, Ours TM, Vaezi MF, Richter JE. Long-term effect of H2RA therapy on nocturnal gastric acid breakthrough. Gastroenterology 2002;122:625-632.

8. Ours TM, Fackler WK, Richter JE, Vaezi MF. Nocturnal acid breakthrough: clinical significance and correlation with esophageal acid exposure. Am J Gastroenterol 2003;98:545-550.

9. Klinkenberg-Knol EC, Meuwissen SG. Combined gastric and oesophageal 24-hour $\mathrm{pH}$ monitoring and oesophageal manometry in patients with reflux disease, resistant to treatment with omeprazole. Aliment Pharmacol Ther 1990;4:485-495.

10. Khan MQ, Alaraj A, Alsohaibani F, Al-Kahtani K, Jbarah S, Al-Ashgar H. Diagnostic utility of impedance-pH monitoring in refractory nonerosive reflux disease. J Neurogastroenterol Motil 2014;20:497-505.

11. Vela MF, Camacho-Lobato L, Srinivasan R, Tutuian R, Katz PO, Castell DO. Simultaneous intraesophageal impedance and $\mathrm{pH}$ measurement of acid and nonacid gastroesophageal reflux: effect of omeprazole. Gastroenterology 2001;120:1599-1606.

12. Mainie I, Tutuian R, Shay S, et al. Acid and non-acid reflux in patients with persistent symptoms despite acid suppressive therapy: a multicentre study using combined ambulatory impedance-pH monitoring. Gut 2006;5 5:1398-1402.

13. Kil BJ, Kim IW, Shin CY, et al. Comparison of IY81149 with omeprazole in rat reflux oesophagitis. J Auton Pharmacol 2000;20:291-296.

14. Shay S, Tutuian R, Sifrim D, et al. Twenty-four hour ambulatory simultaneous impedance and $\mathrm{pH}$ monitoring: a multicenter report of normal values from 60 healthy volunteers. Am J Gastroenterol 2004;99:10371043.

15. Zentilin P, Iiritano E, Dulbecco P, et al. Normal values of 24-h ambulatory intraluminal impedance combined with $\mathrm{pH}$-metry in subjects eating a Mediterranean diet. Dig Liver Dis 2006;38:226-232.

16. Zerbib F, des Varannes SB, Roman S, et al. Normal values and day-today variability of 24-h ambulatory oesophageal impedance-pH monitoring in a Belgian-French cohort of healthy subjects. Aliment Pharmacol Ther 2005;22:1011-1021.

17. Wang Y, Pan T, Wang Q, Guo Z. Additional bedtime H2-receptor antagonist for the control of nocturnal gastric acid breakthrough. Cochrane 
Database Syst Rev 2009:CD004275.

18. Xue S, Katz PO, Banerjee P, Tutuian R, Castell DO. Bedtime H2 blockers improve nocturnal gastric acid control in GERD patients on proton pump inhibitors. Aliment Pharmacol Ther 2001;15:1351-1356.

19. Peghini PL, Katz PO, Bracy NA, Castell DO. Nocturnal recovery of gastric acid secretion with twice-daily dosing of proton pump inhibitors. Am J Gastroenterol 1998; 93:763-767.

20. Janiak P, Thumshirn M, Menne D, et al. Clinical trial: the effects of adding ranitidine at night to twice daily omeprazole therapy on nocturnal acid breakthrough and acid reflux in patients with systemic sclerosis--a randomized controlled, cross-over trial. Aliment Pharmacol Ther 2007;26:12591265.

21. Yeh RW, Gerson LB, Triadafilopoulos G. Efficacy of esomeprazole in controlling reflux symptoms, intraesophageal, and intragastric $\mathrm{pH}$ in patients with Barrett's esophagus. Dis Esophagus 2003;16:193-198.

22. Oh TH. Atypical manifestation of gastroesophageal reflux disease: a disease with a thousand faces. J Neurogastroenterol Motil 2014;20:1-3.

23. Clayton SB, Rife CC, Singh ER, Kalbfleisch JH, Castell DO. Twicedaily proton pump inhibitor therapy does not decrease the frequency of reflux episodes during nocturnal recumbency in patients with refractory GERD: analysis of 200 patients using multichannel intraluminal impedance-pH testing. Dis Esophagus 2012;25:682-686.

24. Tamhankar AP, Peters JH, Portale G, et al. Omeprazole does not reduce gastroesophageal reflux: new insights using multichannel intraluminal impedance technology. J Gastrointest Surg 2004;8:890-897; discussion 897-898.

25. Yamashita H, Ashida K, Fukuchi T, et al. Combined pH-impedance monitoring and high-resolution manometry of Japanese patients treated with proton-pump inhibitors for persistent symptoms of non-erosive reflux disease. J Smooth Muscle Res 2012;48:125-135.

26. Cho YK. Impedance $\mathrm{pH}$ guided approach to proton pump inhibitorrefractory non-erosive reflux disease. J Neurogastroenterol Motil 2014;20:419-420.

27. Seo KA, Lee SJ, Kim KB, et al. Ilaprazole, a new proton pump inhibitor, is primarily metabolized to ilaprazole sulfone by CYP3A4 and $3 \mathrm{~A} 5$. Xenobiotica 2012;42:278-284.

28. Wang L, Zhou L, Hu H, Lin S, Xia J. Ilaprazole for the treatment of duodenal ulcer: a randomized, double-blind and controlled phase III trial. Curr Med Res Opin 2012;28:101-109.

29. Cho H, Choi MK, Cho DY, et al. Effect of CYP2C19 genetic polymorphism on pharmacokinetics and pharmacodynamics of a new proton pump inhibitor, ilaprazole. J Clin Pharmacol 2012;52:976-984.

30. Li Y, Zhang W, Guo D, Zhou G, Zhou H, Xiao Z. Pharmacokinetics of the new proton pump inhibitor ilaprazole in Chinese healthy subjects in relation to CYP3A5 and CYP2C19 genotypes. Clin Chim Acta 2008;391:60-67.

31. Shin JS, Lee JY, Cho KH, et al. The pharmacokinetics, pharmacodynamics and safety of oral doses of ilaprazole 10, 20 and $40 \mathrm{mg}$ and esomeprazole $40 \mathrm{mg}$ in healthy subjects: a randomised, open-label crossover study. Aliment Pharmacol Ther 2014;40:548-561.

32. de Bortoli N, Martinucci I, Giacchino M, et al. The pharmacokinetics of ilaprazole for gastro-esophageal reflux treatment. Expert Opin Drug Metab Toxicol 2013;9:1361-1369.

33. Stedman CA, Barclay ML. Review article: comparison of the pharmacokinetics, acid suppression and efficacy of proton pump inhibitors. Aliment Pharmacol Ther 2000;14:963-978.

34. Robinson M. Review article: the pharmacodynamics and pharmacokinetics of proton pump inhibitors--overview and clinical implications. Aliment Pharmacol Ther 2004;20(suppl 6):1-10.

35. Miner P Jr, Katz PO, Chen Y, Sostek M. Gastric acid control with esomeprazole, lansoprazole, omeprazole, pantoprazole, and rabeprazole: a five-way crossover study. Am J Gastroenterol 2003;98:2616-2620.

36. Du YQ, Guo WY, Zou DW, et al. Acid inhibition effect of ilaprazole on Helicobacter pylori-negative healthy volunteers: an open randomized cross-over study. J Dig Dis 2012;13:113-119.

37. Periclou AP, Goldwater R, Lee SM, et al. A comparative pharmacodynamic study of IY-81149 versus omeprazole in patients with gastroesophageal reflux disease. Clin Pharmacol Ther 2000;68:304-311.

38. Savarino E, Tutuian R, Zentilin P, et al. Characteristics of reflux episodes and symptom association in patients with erosive esophagitis and nonerosive reflux disease: study using combined impedance-pH off therapy. Am J Gastroenterol 2010;105:1053-1061.

39. Hachem C, Shaheen NJ. Diagnosis and management of functional heartburn. Am J Gastroenterol 2016;111:53-61. 